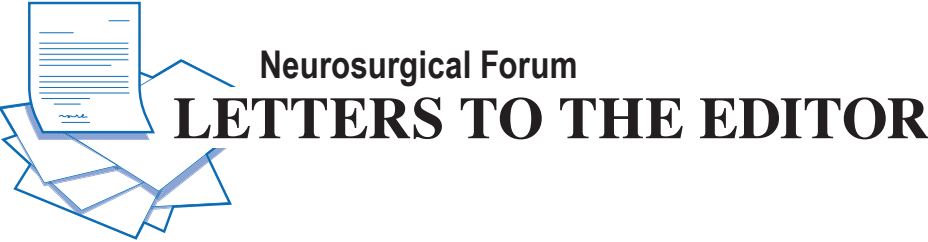

\section{Microvascular decompression for trigeminal neuralgia: does it matter whether the view is through a microscope or via an endoscope?}

TO THE EDITOR: I read with great interest the article by Zagzoog and colleagues ${ }^{2}$ (Zagzoog N, Attar A, Takroni $\mathrm{R}$, et al: Endoscopic versus open microvascular decompression for trigeminal neuralgia: a systematic review and comparative meta-analysis. J Neurosurg [epub ahead of print December 7, 2018; DOI: 10.3171/2018.6.JNS172690]). They performed a systematic review to compare the efficacy and the complications of traditional microvascular decompression (MVD) and totally endoscopic MVD (E-MVD) for trigeminal neuralgia (TN). The resolution available with endoscopic systems is improving, and $4 \mathrm{~K}$ cameras have been introduced to the neurosurgical field as well as other fields. ${ }^{1}$ With high-magnification endoscopic imaging systems and the use of a high-definition monitor, surgeons can grasp minute details of anatomical structure that are sometimes difficult to discern with a surgical microscope, and this advantage can compensate for the lack of depth.

Zagzoog et al. collected data from articles with clinical results of each procedure in at least 10 patients and showed that E-MVD was associated with pain relief comparable to that achieved with traditional MVD, but with fewer complications. They also compared the recurrence of TN in articles published after 2000 with log-rank analysis, and they found no major difference between the 2 modalities. In this survival analysis, they used only data from articles published after 2000 to ensure an equivalent state of health care and medical technology between the 2 comparison groups. However, the authors also note that their comparison of MVD and E-MVD outcomes "includes MVD articles dating from 1995 to 2017." It seems odd to compare surgical results of MVD before 2000, since the modern-day craniotomy resulted in the small surgical corridor size comparable to those needed for EMVD, as the authors describe in the introduction to their article. Moreover, E-MVD would have been performed after some experience with traditional MVD or with supervision of a surgeon with enough experience with traditional MVD, which should create a bias toward better results for E-MVD. Or there could have been publication bias if severe morbidity or mortality occurred when surgeons had just started to perform E-MVD and had not yet had experience with a sufficient number of cases. In TN surgery, the working space is so small that if bleeding occurs under a small craniotomy just large enough for an endoscope, it can be quite difficult to control and can easily end in a critical condition. This situation is different from that of abdominal endoscopic surgery, where the surgeon is operating in a large cavity and can easily obtain a wide opening in an emergency. Hence, we have to be careful to interpret the results of Zagzoog and colleagues' study.

In addition, there are some differences among E-MVD articles, and in some of them the craniotomy that was used is larger than in traditional keyhole MVD; and in such cases, it is not clear what "less invasive" means. Zagzoog et al. concisely depicted the complications of each group in Fig. 4, and it is interesting to see that the incidence of complications is quite different between articles. This suggests that differences between institutions may be more important than differences between E-MVD and traditional MVD. Facial palsy and hearing loss could occur as a result of retracting the cerebellum in the wrong direction, and what we have to consider may be not the question of whether to see the lesion through the microscope or via the endoscope, but rather to see it from a correct and safe direction.

Last, I wonder whether E-MVD can be performed through a $1-\mathrm{cm}$ incision, as described in the authors' introduction. Is this measurement correct?

Because Gamma Knife surgery and nerve block as well as medical therapy can be alternative options for TN, we should focus more on improving the safety of surgery rather than focusing on the pursuit of new devices.

Nevertheless, we do appreciate the authors' effort to clarify the current status of MVD and E-MVD through an extensive analysis.

Toshikazu Kimura, PhD

Japanese Red Cross Medical Center, Tokyo, Japan

\section{References}

1. Rigante M, La Rocca G, Lauretti L, D’Alessandris GQ, Mangiola A, Anile C, et al: Preliminary experience with 4K ultra-high definition endoscope: analysis of pros and cons in skull base surgery. Acta Otorhinolaryngol Ital 37:237-241, 2017 
2. Zagzoog N, Attar A, Takroni R, Alotaibi MB, Reddy K: Endoscopic versus open microvascular decompression for trigeminal neuralgia: a systematic review and comparative meta-analysis. J Neurosurg [epub ahead of print December 7,2018; DOI: 10.3171/2018.6.JNS172690]

\section{Disclosures}

The author reports no conflict of interest.

\section{Correspondence}

Toshikazu Kimura: tkim-tky@umin.ac.jp.

\section{INCLUDE WHEN CITING}

Published online March 22, 2019; DOI: 10.3171/2018.12.JNS183574.

\section{Response}

We are grateful to Dr. Kimura for his interest in our work. We appreciate his thorough review and the excellent points he raises regarding our methodologies and conclusions.

Most of the comments he has set forth are in regard to whether the differences noted between traditional microscope-assisted MVD (M-MVD) or E-MVD used to treat $\mathrm{TN}$ are truly due to differences purely in the surgical procedures or due to compounding factors and whether our study selection criteria may have led to unintentional bias that could have affected our conclusions. We agree that the points that Dr. Kimura raises should be considered when evaluating clinical studies on this topic.

One of the first points that Dr. Kimura raises is the discrepancy in publication years between the M-MVD and E-MVD articles. For our discussion, we wished to perform a perfunctory examination of current techniques used in MVD for treatment of TN, for which modern methods were used in the mid-1990s. The 2 papers included from $1995^{3}$ and $1996^{1}$ varied widely on either side of the M-MVD average for both postsurgical complications and recurrence of pain, with neither skewing the average for the group dramatically. Nevertheless, all statistical comparisons between M-MVD and E-MVD were performed using papers from concurrent years, starting with the year 2000 .

The issue of surgeon experience is interesting, and we agree that it should be important to consider. Unfortunately, most of the articles reviewed for both M-MVD and E-MVD made no mention of surgeon experience, either in years or in numbers of cases previously performed. It is possible that there could be a bias toward more experienced surgeons performing E-MVD procedures. This would be a very interesting topic for future research, if it is possible to attain information on surgical expertise and correlate that to incidence of complications or $\mathrm{TN}$ recurrence. If surgeon inexperience is a primary contributing factor to higher rates of complications and unsuccessful operations, then this would be especially important to determine. Likewise, the factors contributing to the variation in complication and recurrence rates from within the E-MVD or M-MVD groups should be examined as well (these could be related to experience or possibly reflect minor differences in technique) in order to inform best practices for such procedures.

Finally, with regard to Dr. Kimura's question about in- cision size - this is perhaps a matter of the terminology used in our manuscript. For example, the procedure described by Halpern et al. in Minimally Invasive Surgery in 2013 uses a 1-cm incision in the dura through which the endoscope is capable of operating, although the initial skin/musculature incision is $4-6 \mathrm{~cm}^{2}$ We hope this helps clear up any confusion.

Once again, we would like to thank Dr. Kimura for reading our work and for his supportive comments. The considerations raised in our manuscript and in the issues he has mentioned will hopefully lead to standardized practices that improve the safety of TN treatments for patients.

Nirmeen Zagzoog, MD, MSc
Kesh Reddy, MBBS, FRCSC
McMaster University, Hamilton General Hospital, Hamilton,
ON, Canada

\section{References}

1. Barker FG II, Jannetta PJ, Bissonette DJ, Larkins MV, Jho HD: The long-term outcome of microvascular decompression for trigeminal neuralgia. N Engl J Med 334:1077-1083, 1996

2. Halpern CH, Lang SS, Lee JYK: Fully endoscopic microvascular decompression: our early experience. Minim Invasive Surg 2013:739432, 2013

3. Mendoza N, Illingworth RD: Trigeminal neuralgia treated by microvascular decompression: a long-term follow-up study. Br J Neurosurg 9:13-20, 1995

\section{INCLUDE WHEN CITING}

Published online March 22, 2019; DOI: 10.3171/2019.2.JNS1977.

CAANS 2019, except where prohibited by US copyright law

\section{The unmet needs for prognostication of long-term outcomes in multiple sclerosis-related trigeminal neuralgia radiosurgery}

TO THE EDITOR: We have read with great interest the article of Przybylowski and colleagues ${ }^{7}$ on long-term outcomes of facial pain and numbness in patients with multiple sclerosis-related trigeminal neuralgia (MS-TN) after Gamma Knife radiosurgery (GKRS) (Przybylowski CJ, Cole TS, Baranoski JF, et al: Radiosurgery for multiple sclerosis-related trigeminal neuralgia: retrospective review of long-term outcomes. $J$ Neurosurg [epub ahead of print November 30, 2018. DOI: 10.3171/2018.5.JNS173194]). In their retrospective study, the authors demonstrated that GKRS provides good short-term pain control for MS-TN, although worse results were achieved in terms of longterm pain control. ${ }^{7}$ We have recently shown that using a frameless robotic system offers satisfactory pain relief without leading to sensory complications in MS-TN patients. ${ }^{3}$ Nonetheless, in line with Przybylowski et al., ${ }^{7}$ the long-term pain control (48 months after the radiosurgery) was possible in fewer than half of our patients. ${ }^{3}$

Taken together, these results suggest that both frame- 
based, frameless, isocentric, and nonisocentric radiosurgery represents a safe approach to perform trigeminal retrogasserian rhizotomy in MS patients suffering from $\mathrm{TN}$, showing an $85 \%$ rate of pain control within a few weeks. We believe that better long-term pain control can be achieved by delivering higher doses to a longer nerve portion, but at a higher risk of sensory complications.

The last years have been characterized by advances in technology, ${ }^{1,5}$ increasing interest in individualized precision medicine, and in the development of a novel biomarker as well as of objective imaging tools for predicting the clinical outcome of a specific treatment. ${ }^{4,8}$ In this regard, it has been demonstrated that early postsurgical target diffusivity metrics can predict long-term pain relief in patients with TN treated with GKRS. ${ }^{8}$

Considering that long-term pain control remains a challenging issue in MS-TN patients treated with radiosurgery and that demyelination phenomena can occur at the root entry zone, at the intracisternal part of the nerve, and at the retrogasserian area, we believe that diffusion MRI evaluation represents a promising tool to characterize the microstructural changes in myelination and axonal integrity within the trigeminal nerve. Traditional diffusivity metrics such as fractional anisotropy, mean diffusivity, axial diffusivity, and radial diffusivity, as well as novel biomarkers such as the ones provided by the neurite orientation dispersion and density imaging (NODDI) ${ }^{9}$ along with the restricted water fraction provided by the composite hindered and restricted model of diffusion ${ }^{2}$ can therefore be used not only to precisely characterize the microstructural complexity of the trigeminal nerve in this setting of patients but also to predict the chance of long-term pain relief at the individual level.

In this regard, we have recently begun to employ high angular resolution diffusion imaging 6 modeling combined with track density imaging in order to improve the radiosurgery planning in patients with MS-TN and to predict both the short- and long-term pain control in this setting of patients, achieving satisfactory preliminary results.

In an era of precision medicine, we believe that diffusion MRI may represent a promising tool for reliable planning and prognostic evaluation, fostering personalized treatment decision-making. Therefore, prospective trials focusing on this approach in large series of $\mathrm{TN}$ patients are warranted.

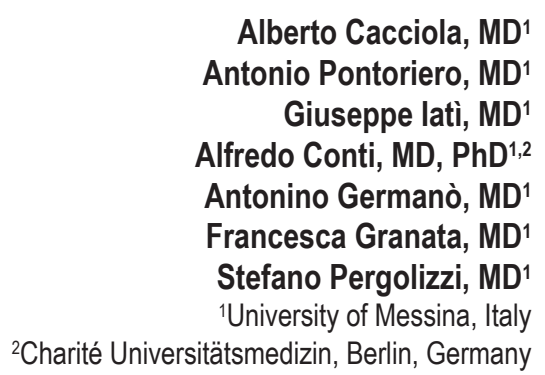

\section{References}

1. Amato E, Italiano A, Pergolizzi S: Gold nanoparticles as a sensitising agent in external beam radiotherapy and brachytherapy: a feasibility study through Monte Carlo simulation. Int J Nanotechnol 10:1045-1054, 2013
2. Assaf Y, Basser PJ: Composite hindered and restricted model of diffusion (CHARMED) MR imaging of the human brain. Neuroimage 27:48-58, 2005

3. Conti A, Pontoriero A, Iatì G, Esposito F, Siniscalchi EN, Crimi S, et al: Frameless stereotactic radiosurgery for treatment of multiple sclerosis-related trigeminal neuralgia. World Neurosurg 103:702-712, 2017

4. Conti A, Pontoriero A, Siddi F, Iatì G, Cardali S, Angileri FF, et al: Post-treatment edema after meningioma radiosurgery is a predictable complication. Cureus 8:e605, 2016

5. Maisano R, Pergolizzi S, Cascinu S: Novel therapeutic approaches to cancer patients with bone metastasis. Crit Rev Oncol Hematol 40:239-250, 2001

6. Milardi D, Cacciola A, Cutroneo G, Marino S, Irrera M, Cacciola G, et al: Red nucleus connectivity as revealed by constrained spherical deconvolution tractography. Neurosci Lett 626:68-73, 2016

7. Przybylowski CJ, Cole TS, Baranoski JF, Little AS, Smith KA, Shetter AG: Radiosurgery for multiple sclerosis-related trigeminal neuralgia: retrospective review of long-term outcomes. J Neurosurg [epub ahead of print November 30, 2018. DOI: 10.3171/2018.5.JNS173194]

8. Tohyama S, Hung PSP, Zhong J, Hodaie M: Early postsurgical diffusivity metrics for prognostication of long-term pain relief after Gamma Knife radiosurgery for trigeminal neuralgia. J Neurosurg 131:539-548, 2019

9. Zhang H, Schneider T, Wheeler-Kingshott CA, Alexander DC: NODDI: practical in vivo neurite orientation dispersion and density imaging of the human brain. Neuroimage 61:1000-1016, 2012

\section{Disclosures}

The authors report no conflict of interest.

\section{Correspondence}

Alberto Cacciola: alberto.cacciola0@gmail.com.

\section{INCLUDE WHEN CITING}

Published online July 19, 2019; DOI: 10.3171/2019.2.JNS19426.

\section{Response}

We thank Cacciola and colleagues for their letter to the editor in response to our publication, "Radiosurgery for multiple sclerosis-related trigeminal neuralgia: retrospective review of long-term outcomes." In our study of 42 patients who underwent Gamma Knife radiosurgery (GKRS) for MS-TN with a median follow-up period of 78 months (range 36-226 months), we found that the index radiosurgery procedure offered acceptable short-term pain control (actuarial pain control 62\% at 1 year) but was less likely to provide long-term pain control (actuarial pain control $22 \%$ at 5 years) when used alone. Cacciola and colleagues have published their results after treating 27 patients with MS-TN using the frameless, nonisocentric CyberKnife radiosurgery system and a median follow-up period of 37 months. ${ }^{1}$ With allowances for differences in patient numbers and follow-up times, it is interesting to note that, despite the use of a different radiosurgical technique, they reported a similar long-term pain control rate after the index radiosurgery procedure ( $44 \%$ pain control at 4 years).

We agree with the authors' notion that a higher radiation dose would be likely to improve the pain control 
success rates after MS-TN radiosurgery but at the cost of increased facial numbness. Because the main appeal of GKRS is the low incidence of facial sensory loss, we have preferred to be conservative in our dosing, typically treating patients with maximum doses of $85 \mathrm{~Gy}$ and $50 \mathrm{~Gy}$ for index and salvage radiosurgery procedures, respectively. This treatment algorithm, in our opinion, represents an acceptable compromise between achieving pain control and preventing facial numbness. If the goal of surgery is to intentionally produce facial numbness, which may be necessary to achieve pain control in some patients, percutaneous thermal rhizotomy is our procedure of choice, since the numbness can be graded and confined to the trigeminal divisions with pain. However, in light of the findings by Flickinger et al., ${ }^{2}$ who demonstrated through a prospective, randomized trial that treating typical trigeminal neuralgia with 2 isocenters did not improve pain control (but did lead to increased facial numbness) compared with 1 isocenter, we feel that treating a longer segment of the nerve is unlikely to be beneficial.

We have no experience using diffusion imaging in the context of TN radiosurgery, but we agree that the techniques discussed by Cacciola and colleagues are worthy of further study. We await the future results of their use of high angular resolution diffusion MRI, and we hope that new imaging modalities will improve our ability to predict the degree of effectiveness and duration of pain control in MS-TN radiosurgery.

Colin J. Przybylowski, MD Jacob F. Baranoski, MD Andrew S. Little, MD Andrew G. Shetter, MD On behalf of the authors Barrow Neurological Institute, St. Joseph's Hospital and Medical Center, Phoenix, AZ

\section{Acknowledgments}

The authors thank the staff of Neuroscience Publications at Barrow Neurological Institute for assistance with manuscript preparation.

\section{References}

1. Conti A, Pontoriero A, Iatì G, Esposito F, Siniscalchi EN, Crimi S, et al: Frameless stereotactic radiosurgery for treatment of multiple sclerosis-related trigeminal neuralgia. World Neurosurg 103:702-712, 2017

2. Flickinger JC, Pollock BE, Kondziolka D, Phuong LK, Foote RL, Stafford SL, et al: Does increased nerve length within the treatment volume improve trigeminal neuralgia radiosurgery? A prospective double-blind, randomized study. Int J Radiat Oncol Biol Phys 51:449-454, 2001

\section{Disclosures}

Dr. Little is a shareholder in Kogent Surgical.

\section{INCLUDE WHEN CITING}

Published online July 19, 2019; DOI: 10.3171/2019.3.JNS19486.

@AANS 2019, except where prohibited by US copyright law

\section{Classic radiological appearance of a carotid web}

TO THE EDITOR: The article by Vercelli and colleagues $^{3}$ (Vercelli GG, Campeau NG, Macedo TA, et al: De novo formation of a carotid web: case report. J Neurosurg [epub ahead of print November 30, 2018. DOI: 10.3171/2018.7.JNS181579]) presents a 47-year-old man with presumed de novo formation of a carotid artery web. We find the authors' hypothesis interesting, and we think that the ensuing discussion is a worthwhile contribution, but there is one particular aspect of the manuscript that needs elaboration.

The article describes the de novo formation of a shelflike structure along the posterior wall of the internal carotid artery (ICA) with the "classic radiological appearance" of a carotid artery web and suggests that this web arose from an arterial dissection. We agree that the posterior wall of the ICA is typically the location for a carotid artery web. However, our experience and evidence in the existing literature suggest that the typical location is more specifically along the posterior wall at the proximal aspect of the carotid artery bulb (Fig. 1 left) rather than at the distal aspect. The lesion in the manuscript is located at the distal aspect of the bulb (Fig. 1 right), not at the usual location for a carotid artery web.

The location and morphology of the lesion are indeed more consistent with the residua of an arterial dissection.

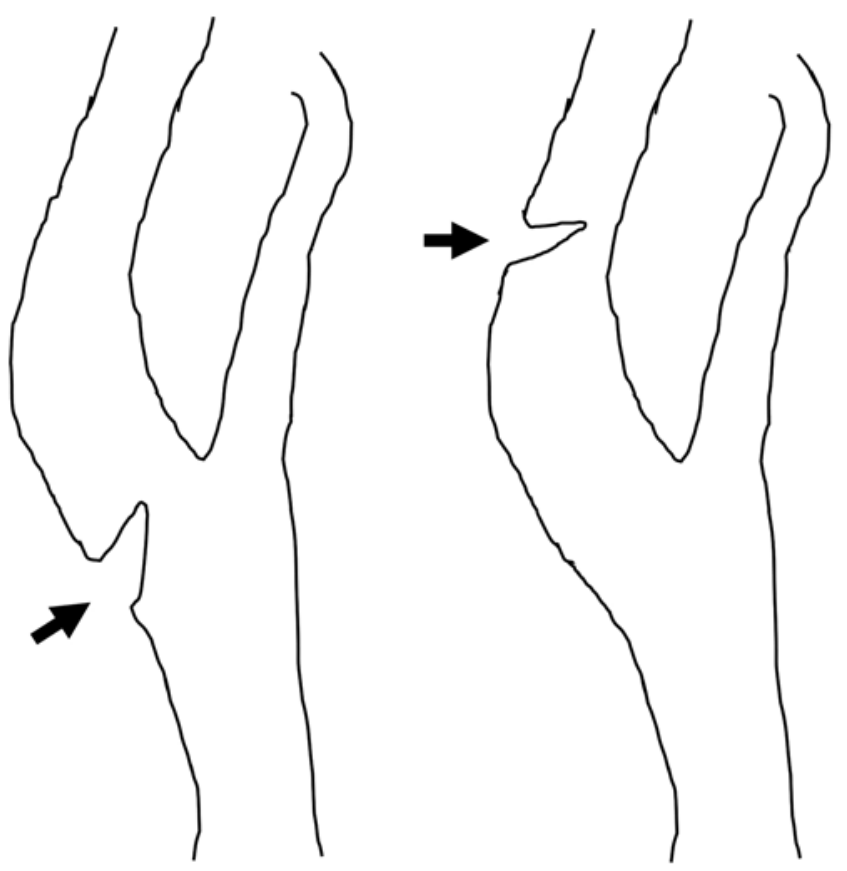

FIG 1. Left: The typical location of a carotid artery web is at the posterior wall of the proximal aspect (arrow) of the carotid bulb. Right: The lesion described by Vercelli and colleagues is located at the distal aspect (arrow) of the carotid bulb. 
ICA dissections are typically located distal to the carotid artery bulb, and the most proximal part of a dissection does not extend more proximally than this transition zone, where the elastic type of the artery changes into the muscular type. ${ }^{2}$

Previously reported histological findings ${ }^{1}$ describe a dissection splitting the intima in two surgically resected carotid artery webs, but it remains unclear whether focal microdissection leads to carotid artery web formation or whether it occurs secondary to the hemodynamic or arterial wall abnormality from a preexisting web.

Again, we agree that the presented case is interesting. However, we do not think that the entity described in the manuscript is a carotid artery web, at least not a typical one.

$$
\begin{array}{r}
\text { Valeria Guglielmi, MD } \\
\text { Amsterdam UMC, University of Amsterdam, Amsterdam, } \\
\text { The Netherlands }
\end{array}
$$

Daniel M. Mandell, MD, PhD Toronto Western Hospital and the University of Toronto, Toronto, ON, Canada

\section{References}

1. Choi PM, Singh D, Trivedi A, Qazi E, George D, Wong J, et al: Carotid webs and recurrent ischemic strokes in the era of CT angiography. AJNR Am J Neuroradiol 36:2134-2139, 2015

2. Müller BT, Luther B, Hort W, Neumann-Haefelin T, Aulich A, Sandmann W: Surgical treatment of 50 carotid dissections: indications and results. J Vasc Surg 31:980-988, 2000

3. Vercelli GG, Campeau NG, Macedo TA, Dawson ET, Lanzino G: De novo formation of a carotid web: case report. J Neurosurg [epub ahead of print November 30, 2018. DOI: 10.3171/2018.7.JNS181579]

\section{Disclosures}

The authors report no conflict of interest.

\section{Correspondence}

Daniel Mandell: danny.mandell@uhn.ca.

INCLUDE WHEN CITING

Published online April 5, 2019; DOI: 10.3171/2018.12.JNS183522.

\section{Response}

We thank Drs. Guglielmi and Mandell for their interest in our case and their insightful comments. The location of the anomaly in our patient might have been a few millimeters more distal than the "typical" carotid artery web. We acknowledge that the exact definition of a carotid artery web is a matter of controversy, and a cursory review of the most recent literature reveals a few cases with locations similar to the one we have encountered. ${ }^{2,3}$ Definitely the radiological evolution at follow-up on the axial and 3D reconstructions of the CTA studies in our patient is strongly suggestive of a carotid artery web. The etiopathogenesis of carotid artery webs remains elusive. Our case suggests a possible hypothesis, supported, in part, by the histology findings of some of the cases reported by Choi and coworkers. ${ }^{1}$

\section{Giovanni G. Vercelli, MD \\ Mayo Clinic, Rochester, MN \\ Città della Salute e della Scienza di Torino, Torino, Italy}

Giuseppe Lanzino, MD

Mayo Clinic, Rochester, MN

\section{References}

1. Choi PM, Singh D, Trivedi A, Qazi E, George D, Wong J, et al: Carotid webs and recurrent ischemic strokes in the era of CT angiography. AJNR Am J Neuroradiol 36:2134-2139, 2015

2. Fu W, Crockett A, Low G, Patel V: Internal carotid artery web: Doppler ultrasound with CT angiography correlation. J Radiol Case Rep 9:1-6, 2015

3. Haussen DC, Grossberg JA, Koch S, Malik A, Yavagal D, Gory B, et al: Multicenter experience with stenting for symptomatic carotid web. Interv Neurol 7:413-418, 2018

INCLUDE WHEN CITING

Published online April 5, 2019; DOI: 10.3171/2019.2.JNS183581.

CAANS 2019, except where prohibited by US copyright law

\section{Prediction of rebleeding after aneurysmal subarachnoid hemorrhage}

TO THE EDITOR: With great appreciation and interest we recently read the article by Darkwah Oppong et al. ${ }^{2}$ (Darkwah Oppong M, Gümüs M, Pierscianek D, et al: Aneurysm rebleeding before therapy: a predictable disaster? J Neurosurg [epub ahead of print November 30, 2018. DOI: 10.3171/2018.7.JNS181119]) about prediction of aneurysm rebleeding. The results of their study showed that premorbid hypertension, basilar artery aneurysm, larger aneurysm size, intracerebral hemorrhage, and acute hydrocephalus were independently correlated with rebleeding after aneurysmal subarachnoid hemorrhage (SAH). Moreover, the authors also built a 9-point prediction score based on those 5 predictors.

Rebleeding is strongly correlated with poor outcome in patients with aneurysmal SAH. ${ }^{3}$ Because patients with aneurysmal SAH are at high risk of rebleeding in the first 24 hours after initial bleeding, early identification and appropriate treatment are important to improve their outcome. ${ }^{5}$ In Darkwah Oppong et al.'s study, 5 simple predictors of aneurysm rebleeding were found and a prediction score with good accuracy was developed. These findings will be helpful to the early management of aneurysmal SAH. However, some issues still need to be noticed in this study.

First, some potential predictors of aneurysm rebleeding were not analyzed. As mentioned by the authors, sentinel headache was reported to be independently correlated with rebleeding after aneurysmal SAH in the study by Beck et al. ${ }^{1}$ In addition, early seizure and consciousness disorder were also shown as independent predictors of aneurysm rebleeding in Solanki et al.'s study. ${ }^{6}$ Adding these clinical parameters may improve the rebleeding predic- 
tion after aneurysmal SAH. Moreover, the original Fisher grade, instead of the modified Fisher grade, was adopted in this study, and was not found to be independently associated with aneurysm rebleeding. However, the modified Fisher grade was an independent predictor of rebleeding after aneurysmal SAH in another study by van Donkelaar et al. 7 Therefore, it is meaningful to explore the role of the modified Fisher grade in predicting aneurysm rebleeding in their cohort. Furthermore, the authors evaluated intraventricular hemorrhage by using the original Graeb score. Compared to the original Graeb score, the modified Graeb score may reflect the severity of intraventricular hemorrhage more accurately. ${ }^{4}$ It would have been interesting to investigate whether the modified Graeb score is related to rebleeding after aneurysmal SAH in this study.

In conclusion, the study by Darkwah Oppong et al. is important for early recognition of patients at high risk of aneurysm rebleeding. It is necessary to confirm their findings in further studies.

Zhiyuan Yu, MD
Jun Zheng, MD
Lu Ma, MD
Chao You, MD
Hao Li, PhD
West China Hospital, Sichuan University, Sichuan, China

\section{References}

1. Beck J, Raabe A, Szelenyi A, Berkefeld J, Gerlach R, Setzer $\mathrm{M}$, et al: Sentinel headache and the risk of rebleeding after aneurysmal subarachnoid hemorrhage. Stroke 37:2733-2737, 2006

2. Darkwah Oppong M, Gümüs M, Pierscianek D, Herten A, Kneist A, Wrede K, et al: Aneurysm rebleeding before therapy: a predictable disaster? J Neurosurg [epub ahead of print November 30, 2018. DOI: 10.3171/2018.7.JNS181119]

3. Lord AS, Fernandez L, Schmidt JM, Mayer SA, Claassen J, Lee K, et al: Effect of rebleeding on the course and incidence of vasospasm after subarachnoid hemorrhage. Neurology 78:31-37, 2012

4. Morgan TC, Dawson J, Spengler D, Lees KR, Aldrich C, Mishra NK, et al: The Modified Graeb Score: an enhanced tool for intraventricular hemorrhage measurement and prediction of functional outcome. Stroke 44:635-641, 2013

5. Naidech AM, Janjua N, Kreiter KT, Ostapkovich ND, Fitzsimmons BF, Parra A, et al: Predictors and impact of aneurysm rebleeding after subarachnoid hemorrhage. Arch Neurol 62:410-416, 2005

6. Solanki C, Pandey P, Rao KV: Predictors of aneurysmal rebleed before definitive surgical or endovascular management. Acta Neurochir (Wien) 158:1037-1044, 2016

7. van Donkelaar CE, Bakker NA, Veeger NJGM, Uyttenboogaart M, Metzemaekers JD, Luijckx GJ, et al: Predictive factors for rebleeding after aneurysmal subarachnoid hemorrhage: rebleeding aneurysmal subarachnoid hemorrhage study. Stroke 46:2100-2106, 2015

\section{Disclosures}

The authors report no conflict of interest.

\section{Correspondence}

Hao Li: ns_lihao@126.com.

\section{INCLUDE WHEN CITING}

Published online February 15, 2019; DOI: 10.3171/2018.12.JNS183460.

\section{Response}

We greatly appreciate the thoughtful comments by $\mathrm{Li}$ et al. regarding our article. $\mathrm{Li}$ et al. provide insights into further factors that might help to identify patients at risk for aneurysm rebleeding after SAH.

We strongly agree that a sentinel headache event before the initial bleeding might be a very important risk factor for aneurysm rebleeding, as reported by Beck et al. ${ }^{1} \mathrm{Ad}-$ ditionally, the role of early loss of consciousness as well as seizures at first bleeding deserves further investigation. However, as mentioned in our discussion of limitations, these parameters are hard to evaluate properly in a retrospective cohort. In addition, there is a risk for false-negative assessment of sentinel headache events, particularly in patients with SAH with poor initial clinical condition, who are more prone to rebleeding. This information bias cannot be fully ruled out even in a prospective SAH cohort.

We aimed to create an easy and quickly calculable tool that allows physicians to assess individual patients' risk for rebleeding. For this reason, continuous and categorical variables (like the original Graeb score ${ }^{5}$ and the Fisher scale $^{3}$ ) were dichotomized for further evaluation of rebleeding risk. Therefore, eventual advantages of the modified scores over the original ones stated by $\mathrm{Li}$ et al. are less likely to carry any additional weight by this approach. Finally, the modified scores are less established and might be more time-consuming (modified Graeb Score ${ }^{7}$ ); this also applied to various modifications of the Fisher scale (modified Fisher scale, ${ }^{4}$ Hijdra scale,${ }^{6}$ Claassen scale ${ }^{2}$ ).

In summary, we want to thank $\mathrm{Li}$ et al. for their important remarks and nice words. We are currently working on a validation of the score in a prospective cohort. The above-mentioned additional parameters will be considered during the further evaluation of the proposed risk score for aneurysm rebleeding.

\section{Marvin Darkwah Oppong, MD Ulrich Sure, MD \\ Ramazan Jabbarli, MD University Hospital, University of Duisburg-Essen, Essen, Germany}

\section{References}

1. Beck J, Raabe A, Szelenyi A, Berkefeld J, Gerlach R, Setzer $\mathrm{M}$, et al: Sentinel headache and the risk of rebleeding after aneurysmal subarachnoid hemorrhage. Stroke 37:2733-2737, 2006

2. Claassen J, Bernardini GL, Kreiter K, Bates J, Du YE, Copeland D, et al: Effect of cisternal and ventricular blood on risk of delayed cerebral ischemia after subarachnoid hemorrhage: the Fisher scale revisited. Stroke 32:2012-2020, 2001

3. Fisher CM, Kistler JP, Davis JM: Relation of cerebral vasospasm to subarachnoid hemorrhage visualized by computerized tomographic scanning. Neurosurgery 6:1-9, 1980

4. Frontera JA, Claassen J, Schmidt JM, Wartenberg KE, Temes $\mathrm{R}$, Connolly ES Jr, et al: Prediction of symptomatic vasospasm after subarachnoid hemorrhage: the modified Fisher scale. Neurosurgery 59:21-27, 2006

5. Graeb DA, Robertson WD, Lapointe JS, Nugent RA, Harrison PB: Computed tomographic diagnosis of intraventricular 
hemorrhage. Etiology and prognosis. Radiology 143:91-96, 1982

6. Hijdra A, Brouwers PJ, Vermeulen M, van Gijn J: Grading the amount of blood on computed tomograms after subarachnoid hemorrhage. Stroke 21:1156-1161, 1990

7. Morgan TC, Dawson J, Spengler D, Lees KR, Aldrich C, Mishra NK, et al: The Modified Graeb Score: an enhanced tool for intraventricular hemorrhage measurement and prediction of functional outcome. Stroke 44:635-641, 2013

\section{INCLUDE WHEN CITING}

Published online February 15, 2019; DOI: 10.3171/2018.12.JNS183520.

CAANS 2019, except where prohibited by US copyright law

\section{Insular glioma surgery}

TO THE EDITOR: We read with great enthusiasm the review published by Hervey-Jumper and Berger on insular glioma surgery ${ }^{3}$ (Hervey-Jumper SL, Berger MS: Insular glioma surgery: an evolution of thought and practice. J Neurosurg 130:9-16, January 2019). The authors provide a comprehensive historical review about the anatomical and functional aspects of insular glioma surgery, its outcomes, and their personal expert view on the technical nuances, highlighting the role played by tumor histology and vascular injury in the outcome.

Our group supports the use of augmented reality (AR) combining morphological and functional information in insular glioma resection to improve the surgical planning, the intraoperative technical management, and to predict the functional outcome.

The insular arteries supply the insular cortex, ${ }^{1}$ extreme capsule and, rarely, the claustrum and external capsule. Although the preservation of the arteries of the insula in the dominant hemisphere is crucial (language-related tracts), the potential vascular relation with the corticospinal tract is paramount given the implications of a dense motor deficit in the adjuvant treatment and overall survival in patients with high-grade gliomas. ${ }^{3,4}$

We are aware of the limitations of microscope-navigated $\mathrm{AR}$, in particular the intraoperative brain shift, ${ }^{2}$ the incomplete identification of the lenticulostriate arteries (LSAs) given the limitations of the 3D time-of-flight (TOF) MRI, 7 and the variation in tractography processing algorithms. ${ }^{6}$ Therefore, AR is used as a surgical guide to increase awareness of the anatomical structures that is integrated with the intraoperative neuromonitoring (continuous motor evoked potentials provided by the subdural strip electrodes, cortical monopolar mapping, and continuous subcortical mapping with suction probe) and provisional diagnosis (intraoperative cytological smear). Conventional angiography, ${ }^{5}$ 3D TOF MRI sequence, ${ }^{7}$ 3D ultrasound, ${ }^{8}$ and micro-Doppler ${ }^{9}$ have also been described as useful for a better understanding of the vascular relations of the insular tumors with the $\mathrm{M}_{2} / \mathrm{M}_{3}$ branches and perforators, thereby assisting in prevention of vascular injuries. However, several limitations were pointed to regarding these methods, particularly the variability in number of LSAs identified by each method, thus reinforcing the role of a multimodality approach.
Hervey-Jumper and Berger ${ }^{3}$ recognize the relevance of these methods in assisting the resection and minimizing the postoperative morbidity, and they also recognize the role of the LSAs as the medial boundary of insular glioma resection. Our group supports the use of AR during the cortical window approach to provide a better understanding of the cortical, subcortical, and vascular functional anatomy in tailoring the surgical approach and the extent of resection.

\section{José Pedro Lavrador, MD \\ Prajwal Ghimire, MRCSEd, MSc \\ Richard Gullan, FRCP, FRCS \\ Keyoumars Ashkan, MD, FRCP, FRCS \\ Francesco Vergani, MD, PhD, FRCS \\ Ranjeev Singh Bhangoo, FRCS \\ King's College Hospital, London, United Kingdom}

\section{References}

1. Benet A, Hervey-Jumper SL, Sánchez JJ, Lawton MT, Berger MS: Surgical assessment of the insula. Part 1: surgical anatomy and morphometric analysis of the transsylvian and transcortical approaches to the insula. J Neurosurg 124:469-481, 2016

2. Gerard IJ, Kersten-Oertel M, Petrecca K, Sirhan D, Hall JA, Collins DL: Brain shift in neuronavigation of brain tumors: a review. Med Image Anal 35:403-420, 2017

3. Hervey-Jumper SL, Berger MS: Insular glioma surgery: an evolution of thought and practice. J Neurosurg 130:9-16, 2019

4. Hervey-Jumper SL, Li J, Osorio JA, Lau D, Molinaro AM, Benet A, Berger MS: Surgical assessment of the insula. Part 2: validation of the Berger-Sanai zone classification system for predicting extent of glioma resection. J Neurosurg 124:482-488, 2016

5. Moshel YA, Marcus JD, Parker EC, Kelly PJ: Resection of insular gliomas: the importance of lenticulostriate artery position. J Neurosurg 109:825-834, 2008

6. Pujol S, Wells W, Pierpaoli C, Brun C, Gee J, Cheng G, et al: The DTI challenge: toward standardized evaluation of diffusion tensor imaging tractography for neurosurgery. J Neuroimaging 25:875-882, 2015

7. Saito R, Kumabe T, Inoue T, Takada S, Yamashita Y, Kanamori M: Magnetic resonance imaging for preoperative identification of the lenticulostriate arteries in insular glioma surgery. Technical note. J Neurosurg 111:278-281, 2009

8. Šteňo A, Jezberová M, Hollý V, Timárová G, Šteňo J: Visualization of lenticulostriate arteries during insular low-grade glioma surgeries by navigated 3D ultrasound power Doppler: technical note. J Neurosurg 125:1016-1023, 2016

9. Yaşargil MG, Krisht AF, Türe U, Al-Mefty O, Yaşargil D: Microsurgery of insular gliomas: Part IV: Surgical treatment and outcome. Contemporary Neurosurg 24:1-8, 2002

\section{Disclosures}

The authors report no conflict of interest.

\section{Correspondence}

Prajwal Ghimire: prajwal.ghimire@nhs.net.

INCLUDE WHEN CITING

Published online August 30, 2019; DOI: 10.3171/2019.4.JNS19760. 


\section{Response}

We appreciate the comments made by our colleagues in the UK and support AR as a strategy and as a useful adjunct to enhance the results of insular glioma surgery.

Mitchel S. Berger, MD

University of California, San Francisco, CA

INCLUDE WHEN CITING

Published online August 30, 2019; DOI: 10.3171/2019.6.JNS19967.

CAANS 2019, except where prohibited by US copyright law 